\title{
Treatment of uniocular aphakia A comparison of iris clip lenses with hard corneal contact lenses
}

\author{
S. P. B. PERCIVAL AND K. M. YOUSEF \\ From Scarborough Hospital, Scarborough
}

Since I 949 (Ridley, I 95 I) attempts have been made to correct uniocular aphakia by insertion of a lens intraocularly. Results from using angle-supported lenses have been uniformly poor, mainly because of damage to the corneal endothelium and to the trabecular mesh-work. Iris-supported lenses were used with success during the I 960 s (Binkhorst and Leonard, 1967; Dallas, 1970). These lenses did not produce glaucoma but because of problems arising from lens dislocation and late corneal oedema most surgeons still preferred either to leave the uniocular cataract untouched or after extraction to substitute a contact lens.

It is well known that elderly patients are often intolerant of aphakic glasses and contact lenses, and Jaffe (1975a) stated that for patients over the age of 67 years intraocular lenses were more suitable. It is not disputed that the intraocular lens is often the treatment of choice in such an age group, but with improvements in microsurgical technique and design of the lens, the problems encountered in younger patients have been largely overcome and short-term visual results have been considerably improved. It is therefore the purpose of this paper to compare the results using intraocular lenses and hard corneal contact lenses in a predominantly presenile age group.

\section{Material and methods}

Twenty-five consecutive patients with uniocular pseudophakia aged between 55 and 75 years at the time of surgery (Group A) were matched as closely as possible for age and sex (Table I) with 25 patients who were offered a conventional hard contact lens trial for uniocular aphakia (Group B). Twenty of Group B were consecutive cases and the contact lens trial was offered postoperatively, two entered the trial between one and two years after surgery, and three entered more than two years after surgery. Criteria for entry were an absence of preoperative macular degeneration, glaucoma, high myopia, and diabetes mellitus, and they had to have a corrected visual acuity of $6 / 12$ or better in the fellow eye. The mean age at the time of surgery for Group $A$ was 66.3 years and at the time of entry for Group B, 67.5 years.

Address for reprints: S. P. B. Percival, FRCS, Consultant Ophthalmic Surgeon, Scarborough Hospital, Scarborough, North Yorkshire YO12 6LQ
The standard cataract extraction was carried out under general anaesthesia using an ab externo microsurgical step incision, six or seven preplaced sutures, chymotrypsin, two peripheral iridectomies, intracapsular cryoextraction, and re-formation of the anterior chamber with Miochol. In addition in Group $A$ a four-loop Binkhorst iris clip lens was inserted, the anterior superior loop being sutured to the iris midstroma with ro/o Perlon. These patients also received subconjunctival Depomedrone and framycetin at the end of the operation, and the majority of those under the age of 70 years received preoperative intravenous mannitol and hyperventilation anaesthesia. Postoperatively betamethasone was begun on the fifth day and used for six to eight weeks in both groups and pilocarpine 2 per cent was instilled daily for at least six months in Group A.

Postoperative examination included slit-lamp assessment for uveitis and iris atrophy, applanation tonometry, visual acuity for near and distance, and assessment of binocularity using the Wirt stereotest. Macular oedema did not necessarily show an obvious fundus abnormality, but was confirmed by the presence of macular scotoma on the Amsler recording chart associated with falling visual acuity.

\section{Results}

Of 25 patients offered a conventional hard contact lens trial (Group B), Io (aged between 67 and 74 years) declined chiefly because of apprehension about handling the lenses or losing them. Five other patients abandoned contact lenses after a few months because of difficulty in handling them or discomfort. There were ro patients who were able to wear contact lenses for more than ro hours a day but even so, two of these became erratic and abandoned them after 18 months to two years' wear.

Table I Age and sex

\begin{tabular}{|c|c|c|c|c|}
\hline \multirow{2}{*}{$\begin{array}{l}\text { Age } \\
\text { (years) }\end{array}$} & \multicolumn{2}{|c|}{ Men } & \multicolumn{2}{|c|}{ Women } \\
\hline & $A$ & $B$ & $A$ & $B$ \\
\hline $55-6 I$ & 3 & 2 & 2 & 0 \\
\hline $62-68$ & 5 & 6 & 7 & 5 \\
\hline $69-75$ & 4 & 4 & 4 & 8 \\
\hline Mean & 66 & 65 & 67 & 69 \\
\hline
\end{tabular}


Table II contrasts the disappointment of patients in Group B with the dramatic recovery of vision in Group A. Just three weeks after surgery most of those in Group A were able to see around 6/12 unaided. It will be seen that two years after the operation a patient not wearing glasses was nearly twice as likely to be seeing 6/9 or better in Group A than in Group B.

These satisfactory unaided visual results are related to a consistent lack of postoperative astigmatism possibly reflecting on the surgical technique, involving at least five preplaced sutures before the eye is opened. Postoperative astigmatism was $0.75 \mathrm{D}$ or less compared to the fellow eye in 70 per cent (35 patients) of the whole group, and less than $\mathrm{I}_{5} \mathrm{D}$ in 94 per cent. There were no patients requiring a postoperative cylindrical correction above $2 \cdot 0 \mathrm{D}$.

A general feature of Group A was an improved depth of focus compared to the normal presbyopic eye. Thirteen patients ( 52 per cent) could read N8 unaided, eight of these could read $\mathrm{N}_{5}$ unaided, and four patients ( 16 per cent) could actually see both $6 / 9$ and $\mathrm{N}_{5}$ unaided and did not require postoperative glasses.

Table III shows the best visual potential in the two groups when the patients were using glasses. In assessing acuity a slight adjustment was made for aphakic magnification in that for $6 / 5$ to be recorded all the letters had to be correct for the patient wearing aphakic spectacles, but only the majority for the patient with pseudophakia or a contact lens. Better visual results again were obtained for Group A reflecting an absence of serious complications; at two years 93 per cent of them could see $6 / 9$ or better. Patients in Group B were often disappointed because their operated eye had not been brought into use; of those in whom the vision of the fellow eye had dropped to $6 / 12$ or worse because of progressing cataract only five out of to would wear an aphakic correction at one year, eight out of 10 at two years' postoperation.

Table II Comparison of visual acuity between Group $A$ unaided and Group $B$ unaided or with contact lenses when worn. (Patients given as percentage of numbers followed-up for given period)

\begin{tabular}{|c|c|c|c|c|c|c|c|c|c|c|}
\hline \multirow[b]{3}{*}{ Visual acuity } & \multicolumn{10}{|c|}{ Period of follow-up } \\
\hline & \multicolumn{2}{|c|}{3 weeks } & \multicolumn{2}{|c|}{2 months } & \multicolumn{2}{|c|}{ I year } & \multicolumn{2}{|c|}{2 years } & \multicolumn{2}{|c|}{3 years } \\
\hline & $A$ & $\boldsymbol{B}$ & $A$ & $B$ & $A$ & $\boldsymbol{B}$ & $A$ & $B$ & $A$ & $\boldsymbol{B}$ \\
\hline & $25 *$ & $25 *$ & $25^{*}$ & $25^{*}$ & $25^{*}$ & $25^{*}$ & $14 *$ & $19^{*}$ & $4 *$ & $13^{*}$ \\
\hline \multirow{3}{*}{$\begin{array}{l}<6 / 60 \\
6 / 60-6 / 24 \\
6 / 18-6 / 12 \\
6 / 9 \text { or better }\end{array}$} & 4 & 100 & & 100 & & 60 & & 63 & & 92 \\
\hline & 24 & & 20 & & 20 & & 7 & & 25 & \\
\hline & $\begin{array}{l}56 \\
16\end{array}$ & & $\begin{array}{l}36 \\
44\end{array}$ & & $\begin{array}{l}28 \\
52\end{array}$ & 40 & $\begin{array}{l}21 \\
72\end{array}$ & 37 & $\begin{array}{l}25 \\
50\end{array}$ & 8 \\
\hline
\end{tabular}

*Number of patients
Table III Comparison of best visual acuity between Group $A$ and Group $B$ with additional spectacle correction. (Patients given as percentage of follow-up)

\begin{tabular}{|c|c|c|c|c|c|c|c|c|}
\hline \multirow{4}{*}{ Visual acuity } & \multicolumn{8}{|c|}{ Period of follow-up } \\
\hline & \multicolumn{2}{|c|}{2 months } & \multicolumn{2}{|c|}{ I year } & \multicolumn{2}{|c|}{2 years } & \multicolumn{2}{|c|}{3 years } \\
\hline & $A$ & $B$ & $A$ & $\boldsymbol{B}$ & $A$ & $\boldsymbol{B}$ & $A$ & $\boldsymbol{B}$ \\
\hline & $25^{*}$ & $25^{*}$ & $25^{*}$ & $25^{*}$ & $14^{*}$ & $19^{*}$ & $4^{*}$ & $13^{*}$ \\
\hline $\begin{array}{l}6 / 24-6 / 12 \\
6 / 9-6 / 6 \\
6 / 5\end{array}$ & $\begin{array}{r}4 \\
52 \\
44\end{array}$ & $\begin{array}{l}12 \\
64 \\
24\end{array}$ & $\begin{array}{r}8 \\
60 \\
32\end{array}$ & $\begin{array}{l}12 \\
64 \\
24\end{array}$ & $\begin{array}{r}7 \\
53 \\
40\end{array}$ & $\begin{array}{l}11 \\
63 \\
26\end{array}$ & $\begin{array}{l}25 \\
75\end{array}$ & $\begin{array}{r}8 \\
77 \\
15\end{array}$ \\
\hline \multicolumn{2}{|c|}{$\begin{array}{l}\text { No. not using } \\
\text { aphakic correction }\end{array}$} & $25^{*}$ & & $13^{*}$ & & $9^{*}$ & & $9^{\circ}$ \\
\hline
\end{tabular}

\section{Stereopsis}

Using the Wirt stereotest 17 patients (68 per cent) in Group A regained full stereoscopic vision (to $40^{\prime \prime}$ or $50^{\prime \prime}$ of arc), and all in this group regained stereopsis to $140^{\prime \prime}$ of arc or better. By contrast, in Group B only four of the 10 patients wearing contact lenses regained full stereoscopic vision, three others were stereoscopic to $100^{\prime \prime}$ arc or better, and three were worse than $140^{\prime \prime}$ arc. Girard, Friedman, Moore, Blan, Binkhorst, and Gobin (1962) also reported relatively poor stereopsis with conventional contact lenses ( 46 per cent stereopsis) compared with intraocular lenses $(82$ per cent stereopsis).

Diplopia was never a serious problem but was initially disconcerting for three of the contact lens wearers.

Eikonometry was performed using the Hawkswell eikonometer (Nolan and Hawkswell, 1974) on three of the patients wearing contact lenses. These gave an average reading of $\mathrm{r} \cdot 8$ per cent magnification. The same instrument was used on ro patients from Group $A$ and gave an average reading of 0.2 per cent magnification (range $-I \cdot 7$ to $+\mathrm{I} \cdot 9$ per cent).

\section{Complications}

Complications (Table IV) were not serious and did not show any clear weighting for either group. The single case of corneal oedema was from an illfitting contact lens and was quickly reversed. The case of lens subluxation occurred 22 months after surgery in one of the two patients whose pupil sphincter failed to constrict in the immediate postoperative period. The pupil diameter was $4.5 \mathrm{~mm}$ at the time of subluxation and the reposition of loops was readily corrected by non-surgical means. 
Table IV Complications (50 patients)

\begin{tabular}{llll}
\hline & Group $A$ & & Group B \\
\cline { 2 - 2 } Vitreous loss & I & & I \\
Hyphaema & I & & I \\
Iridocyclitis & 2 & 2 \\
Atonic pupil sphincter & 2 & I \\
Macular oedema & 6 & 3 \\
Corneal oedema & 0 & \\
Subluxation of inferior loop & I & \\
\hline
\end{tabular}

\section{MACULAR OEDEMA}

Some form of clinical macular oedema was noted in 24 per cent of Group $A$ and in 12 per cent of Group B. Visual deterioration began some time between the second and fourteenth postoperative month and in four of Group A it lasted less than three months. Macular oedema may be presumed to have occurred in a larger number of Group B but either at a time when the aphakia was uncorrected or to patients who did not consider the defect to be of any greater significance than the other difficulties of corrected aphakia. Gills (1975) in a review of intraocular lenses found there was an incidence of about 20 per cent of macular oedema, and angiographic evidence of macular oedema is known to develop in 40 to 60 per cent of uncomplicated cataract extractions (Irvine, Bresky, Crowder, Forster, Hunter, and Kulvin, 1971; Toshioka and Kawashima, 1971 ; Hitchings, Chisholm, and Bird, I975), but the mechanism is unknown. Jaffe (1975b) showed that the incidence of macular oedema is similar whether the intra- or extracapsular method of extraction is employed, and in the present series there was no correlation with vitreous traction (as suggested by Irvine, 1953) or with inflammation or vascular disease (as suggested by Gass and Norton, 1966). In only three patients did the visual loss extend to $6 / 24$ or worse (two in Group B, one in Group A). The transient nature of macular oedema is well known (Gass and Norton, 1969; Jacobson and Dellaporta, 1974) and in this series the vision ultimately returned to $6 / 5$ in some and to $6 / 12$ or better in all patients.

\section{Conclusions}

A visual potential in Group $A$ as good as or better than in Group B over a two- or three-year-period of follow-up suggests that in the age group under discussion an intraocular lens is justifiable for all patients with uncomplicated cataract and not merely those with uniocular cataract. In this series more than half the patients with intraocular lenses consistently saw $6 / 9$ or better unaided, and more than 90 per cent saw $6 / 9$ or better with spectacle correction.

Optical advantages of intraocular lenses compared with contact lenses are immediate restoration of sight, better visual acuity, better stereopsis, and an improved depth of focus for the patient.

Macular oedema occurred clinically in 24 per cent of the intraocular lens group and is more likely to produce symptoms than in patients without an implant. However, further research is required to prove that it is more severe than in other patients, and at present it should not be considered a serious complication since, although it may last several months, an eventual return of visual acuity of $6 / 9$ or better may be anticipated.

\section{Summary}

The visual results, stereopsis, and complications have been assessed on 50 patients in a presenile age group treated for uniocular aphakia. Twenty-five patients received a Binkhorst four-loop lens implant at the time of cataract surgery and 25 were offered a conventional hard contact lens trial postoperatively. The period of follow-up ranged from one to three years.

\section{References}

BINKHORST, c. D., and LeONARD, P. A. M. (1967) Amer. F. Ophthal., 64, 947

DALlAS, N. L. (1970) Trans. ophthal. Soc. U.K., 90, 725

GASS, J. D. M., and NORTON, E. W. D. (1966) Arch. Ophthal., 76, 646

- and - (1969) Trans. Amer. Acad. Ophthal. Otolaryng., 73, 665

GILls, J. P. (1975) Contact and Intraocular lens Med. F., I, 339

GIRARD, L. J., FRIEDMAN, B., MOORE, C. D., BLAN, R. I., BINKHORST, C. D., and gobin, M. H. (1962) Arch Ophthal.,

68, 762

hitchings, R. A., Chisholm, 1. H., and BIRD, A. C. (1975) Invest. Ophthal., 14, 68

IRVINE, s. R. (1953) Amer. F. Ophthal., 36, 599

-, BRESKY, R., CROWDER, B. M., FORSTER, R. K., HUNTER, D. M., and KULVIN, s. M. (1971) Ann. Ophthal., 3, 1234 JaCobson, D. R., and Dellaporta, A. (1974) Amer. $\mathcal{Y}$. Ophthal., 77, 445

JAFFe, N. (1975a) Audio $\mathcal{Y}$. Rev. Ophthal., 1, no. 5

(1975b) Communication to meeting of International Intraocular Implant Club, July 1975

NOlan, J., and hawkswell, A. (1974) Trans. ophthal. Soc. U.K., 94, 480

RIDLEY, H. (195I) Ibid., 7I, 6 I 7

Toshioka, H., and kaWashima, K. (197I) Acta Soc. Ophthal. jap., 75, 2269 